\title{
A Comparative Study of Li Qingzhao's and Sappho's Life Experiences
}

\author{
Yimei Du \\ the Department of Foreign Languages and Cultures \\ Oxbridge College of Kunming University of Science and Technology \\ Kunming, China
}

\begin{abstract}
The paper recollects Li Qingzhao's and Sappho's life experiences with a glimpse of their footprints on the way to happiness and true love. The persistent pursuit of true love and unceasing search for a happy life constitute the most important content of the two poets' lives, which also becomes the soul of their works. Although Li Qingzhao's whole life was full of frustrations and Sappho's relatively smooth, they both kept equally persistent faith in a meaningful and happy life.
\end{abstract}

Keywords-comparative study; life experiences; Li Qingzhao; Sappho

\section{INTRODUCTION}

Li Qingzhao (1084-1155AD), her literary name Yi' an Jushi, was one of the distinguished female writers of the Chinese Southern Song Dynasty (1127-1279AD). She is believed to have written about $47 \mathrm{Ci}$-poems or what is also called tuned lyrics written to a certain tune, over 10 Shi-poems and six or seven works in prose, but she is best-known as a $\mathrm{Ci}$ lyricist. Her accomplishments in $\mathrm{Ci}$-poems caused her to be called the "the Master of Ci-poetry" in the history of Chinese literature. Sappho (610-580, BC), acclaimed by Plato as "the Tenth Muse" [1], was assumed to be the earliest poetess of ancient Greece as well as the entire world. Her actual lyrics are supposed to have filled at least nine books of lyrics and one book of elegies ${ }^{1}$, but most of them were destroyed as heretic ideas by church authorities in the Middle Ages. Now only a few fragments have been preserved thanks to citations in different literary or philosophical essays by later writers as well as remnants of ancient papyrus copies excavated from Egypt. Even so, "with respect only to her passions and rhythms, she is unanimously acclaimed as the greatest artist in the world history" [2].

Zhang Siqi's The Comparison between Sappho's and Li Qingzhao's Poems is perhaps one of the few papers dealing with the comparison and contrast between Li Qingzhao and Sappho. In his article Zhang compares and contrasts their poems on their longing for their lovers, their loneliness and natural scenery. While enriching our knowledge of their works and cultures, renewing our feeling experiences and channels of thinking, Zhang's paper arouses the readers' interest in the two lyricists' life experiences. Here this paper attempts to outline $\mathrm{Li}$ Qingzhao's and Sappho's life experiences so that their

1 The fragments mentioned here are numbered by the numeration of the translators. admirers can appreciate their poetic sentiments in a more profound way.

\section{LI QINGZHAO’S FRUSTRATING LIFE EXPERIENCES AND INTRICATE THOUGHTS}

Li Qingzhao not only enjoyed the blissful happy life, but also wandered about in a desperate plight; not only received sweet love from her husband, but also tasted the bitter lovesickness; not only witnessed the prosperous life in the flourishing imperial city, but also saw her country invaded by foreign troops. In all, the first part of her life was sweet and the second bitter. The drastic changeability of her fate had much influence on her feelings and thoughts, the marks of which can all be found in her poems.

At her young age, Li Qingzhao found much interest in books and had won herself good fame for her poetic talents. She was born to a family of officials and scholars in 1084 in what is now Jinan, Shandong Province, China. Her father, Li Gefei was a person of great learning, called "One of the Later Four Students of Su Shi," an eminent thinker and poet of the Song Dynasty. Her mother "was good at composing Ci poems" according to the Famous Women in Chinese History published by Shanghai People's Press in 1988. The thick scholarly environment in the family enabled Li Qingzhao to read widely and acquire an extensive knowledge of ancient Chinese history and literature. Besides books, she had other pastimes, playing chess, dangling on a swing, excursing to the suburbs and nearby beauty spots, boating in the lake and so on. She was extremely sensitive to the beauty of nature, which is vividly described in her A dream Song: A Reminiscence and Complaint Against a Prince: Admiring Lotuses. The two lyrics reveal us beautiful pictures of the lakes dotted with lotuses and egrets and gulls, disclosing the poetess' "girlish naiveté, her lovely untamed spirit and love of nature" [3]. Actually, her poems at this early age had already become well-known to the contemporary elite circles. Chao Buzhi, "One of the Original Four Students of Su Shi", applauds her that Li Qingzhao's "poetic feelings are like the night magpie's singing, which will echo around for three nights" [4]. The carefree youthful life makes Li Qingzhao's early compositions brimming with youthful vigour, confidence and brightness.

With the end of the girlhood came the harmonious marriage life, established on the same passion for poetry and classics. Before their first meeting, Li Qingzhao and her would-be 
husband, Zhao Mingcheng, had become attached to each other for each other's talents. At that time Zhao Mingcheng was a brilliant Imperial University student, whose deep interest was in asking for inscriptions of metals and stones from some contemporary scholar-bureaucrats. He had a huge collection of artistic classics including paintings, calligraphy, poems as well as ancient bronze and stone inscriptions and objects. His good eye for and deep obsession with these classics made him famous among the scholars. And his brilliant talents also came to be known by Li Qingzhao who was always eager to see the outside and get acquainted with persons of great knowledge. On the other hand, her poems and literary gifts had come to be known by Zhao Mingcheng. Thereby, their marriage was based on mutual admirations, which made their marriage life full of pleasantly scholarly atmosphere. They "got on with each other like best friends" [5], drinking teas, guessing the lines in books, singing songs while enjoying plum blossom and touring to the city and its suburbs in search of favorite antiques and rare editions of ancient books. According to Li Qingzhao's own words, they "enjoyed everything but sensual pleasures" [6]. The happy marriage figures in many of her lyrics, for example, Magnolia Flowers (A shorter version), Fisherman's Pride: Early Plum Blossom, Partridge Sky: To the Cassia Flower, which record their cheerful hours, her pursuit of noble and unsullied character and deep love for the culture of the mother country as well.

The pleasant symphony of the marriage life was sometimes mixed with sad notes and the instruments might even break down. Due to Zhao Mingcheng's frequently leaving home on official duties, Li Qingzhao often stayed alone at home, tasting the bitter fruits of loneliness and lovesickness. Besides, they were childless even at the middle age, which might make Zhao Mingcheng consider marrying another woman to beget a male heir, a common practice in his time. The long separation also weakened their emotional bonds. All these incidents increased the anxieties and miseries of Li Qingzhao who hankered after pure, faithful and consistent love. She wrote quite a few lyrics to pour out her solitude, disappointments and distresses like Drunk in the Shade of Flowers: Double Ninth Festival, Nostalgia for Fluting on the Phoenix Terrace: Separation, A Sprig of Plum Blossom: Sorrow of Separation, Rouged Lips: Loneliness, The Charm of a Maiden Singer: Spring Thoughts and Partridge Sky: Solitude. However, Li Qingzhao did not indulge herself in the endless sorrows. Instead, she still kept the courage of life and continued to pursue the perfection of her personality. In A Galaxy of Beauties: White Chrysanthemums, by praising the lasting fragrance of chrysanthemum with plain appearance, she reveals herself as a strong-minded woman with inner beauty, adding to the gloominess in her poems the spirit of fortitude. In 1129, Zhao Mingcheng died of typhoid en route to an official post. It gave a big blow to Li Qingzhao, from which she never recovered, but did not decrease her love for the former, for whom she wrote several elegies, like A Southern Song: In Memoriam, The Lone Wild Goose: Plum Blossom and Remembering the Maid of Qin, to express her deep longings.

Not confined to her lonely chamber, Li Qingzhao' eyes were also fixed on what was happening in the society: the intense struggles between officials, the continuous wars, the loss of territories, the separation of families... All these events take up some space in her lyrics. In the early time of her marriage she had already known the cruelty and intensity of the political fights for the favor of the Emperor. Since the enthronement of Emperor Zhe Zong of the Northern Song Dynasty, the struggles in the imperial court had been increasingly vehement, in which both Li Qingzhao's father and father-in-law were involved. Then the conservative party $\mathrm{Li}$ Geifei belonged to lost, resulting in the deprivation of his official title and banishment from the capital. In order to relieve her father's worries, Li Qingzhao turned to her father-in-law for help, who was of high position in the Progressive Party, only to be refused, which made her bitterly disappointed. Nevertheless, shortly after her father's banishment, she witnessed her father-in-law's death after his defeat in the struggle with other members in the same party. From this incident Li Qingzhao realized how ruthless impact the political struggle might leave on the connections between dear friends and families. In her On the Trail of Sweet Incense: the Seventh Day of the Seventh Lunar Month, to satirize the intensity of political struggle and illustrate the changeability of human fate, she writes, "But whence these sudden changes/Of sun and rain and wind" [7]. When troubled by political disputes internally, the Northern Song Dynasty was also facing hostile neighbors. In 1125, the Jurchen people of the state of Jin marched south across the northern border of the Song Dynasty and forced its government to move its capital to Hangzhou, South of the Yangtze River, marking the beginning of the Southern Song Dynasty (1127-1279). Though it endeavored to expel the invaders, such attempts turned out unsuccessful and in time it concluded a peace treaty recognizing Jin sovereignty over the northern territories and agreed to pay a yearly tribute in silver and silk. But it did not stop the encroaching horses of Jin, finding themselves unblocked by the troops of the Southern Song Dynasty whose emperor had fled. Like many common people, Li Qingzhao escaped to the south, bringing with her the large artistic collections left by deceased Zhao Mingcheng. The precarious wanderings exhausted her both physically and psychologically. Her poems of this period are filled with her longing for her beloved northern hometown, her lament over the great loss of Zhao Mingcheng's collections, her satire on the surrender of the imperial court and her calling for military action to regain the lost land. The famous ones are A Long Melancholy Tune (Autumn Sorrow): Despair, Spring at Wu Ling: Spring Ends, Joy of Eternal Union: Lantern Festival and the regulated poem, Lines Written on a Summer's Day. The addition of her patriotic fervor to her tuned lyrics represents the elevation of her spiritual level. Apart from the graceful lyrics, she finished the compilation of Zhao Mingcheng's unfinished The Records of Ancient Bronze and Stone, making great contributions to the development of our country's epigraphy and sphragistics and wrote Essay on Ci-poetry, an important theoretic work of Ci-lyrics.

In her poems, Li Qingzhao conveys her constant love, her strong heart, her refined tastes, her patriotic sentiment and her pursuit of literary perfection, which like blood giving life to a human body, run through her poems and give them eternally shining life. 


\section{SAPPHO’s SMOOTH LIFE AND DEEP THOUGHTS}

Very few authentic facts of her life have been preserved, nevertheless there are some records left in the work of her contemporaries and posterity that help to restore a rough image of her. Compared with Li Qingzhao, Sappho enjoys a smooth and stable life. She lived on the island of Lesbos situated in the northern Aegean of ancient Greece in the 6th and 7th centuries B.C., when ancient Greece was entering slave society and many city-states of democracy were being built. Lesbos was then the economical and cultural center, boasting beautiful expanse of grassland, clear streams, gentle breeze, bright sunshine, blue sea and starry sky. These natural sights could arouse boundless poetic imaginations. Sappho's fr. 4, the one quoted at the beginning of the paper, pictures a charming moonlit sky, fr. 5, a delightful spot, and fr. 92, the scenic sunset on the plains. Like Li Qingzhao, Sappho knew the cruelty of political struggle. In the principal town of Mytilene of Lesbos, where she spent most of her days, the struggles for power among the nobles were fierce in which her father and her brothers were involved. Because of their defeat, she was forced to live on the island of Sicily for ten years. In her fr. 98 she laments her life in exile[8]. After she came back from the exile, she led a religious group of young girls or unmarried women for worshiping Aphrodite. She taught them music and songs, most of which are about love and marriages. Sappho was married to a wealthy tradesman and had a daughter Cleis, named after her mother. She is supposed to form pure friendship with Alcaeus, her countryman and a famous lyricist. Her fr. 26 records a sincere talk with the latter. With the flourish of business, the ancient Greeks' became more and more concerned about their own interests. In order to gain personal profits, many people went against laws and morals. In her frr. 33, 65, 78 and 98, Sappho makes us clear about her attitudes towards wealth, outside beauty, knowledge, virtues and their connections with man's happiness and worth. As a poetess, Sappho is passionate, penetrating, sympathetic and sensitive. Her subtle feelings towards the maidens in her group brought her the accusation of being a homosexual. "sapphism" and "lesbianism" meaning "sexual orientation of women to other women" are connected with her. Here whether she is a lesbian or not is not the concern. What matters is her desire, jealousy, sweetness, bitterness, great joy and big loss, the common manifestations of romance.

\section{CONCLUSION}

Although they lived in different times and places, Li Qingzhao and Sappho both held the same delicate and intense feelings about the beautiful side of life. They enjoyed the beauty of nature, sang songs of their youth, explored the worth of life, and pursued pure and permanent love. Their poems describe the universal nature of human beings - the need of loving and being loved. That explains why their passions are still touching and engaging even today. They build us a blooming garden of soul. The works without the care for human hearts are like bodies without blood, pale and weak, which will not last long. Having a warm heart to life and writing with souls are the best gifts Sappho and Li Qingzhao send us through time and space.

\section{REFERENCES}

[1] "Sappho: testimonia," Sappho and Alcaeus in Greek Lyric, Trans. D. A. Campbell. Loeb Classical Library, vol. 1, Cambridge, Mass. and London, 1982, p. 49.

[2] Fei Bai, "[Ancient Greece] Sappho," in A Guide to Appreciation of Masterpieces in World Poetry, Guilin, China: Lijiang Publishing House, 1989, p. 12.

[3] Jiaosheng Wang, "Introduction," in The Complete Ci-poems of $\mathrm{Li}$ Qingzhao: A New English Translation, Philadelphia: Department of Oriental Studies, University of Pennsylvania, 1989, p. iv.

[4] Zhu Xiang, Autobiographies of Four Famous Talented Females: Li Qingzhao, Beijing: Guangming Daily Publishing House, 2003, p. 44.

[5] Chen Zumei, Ci-poetry by Li Qingzhao, Beijing: People's Literature Publishing House, 2005, p. 5.

[6] Chen Zumei, "Epilogue to the Records of Ancient Bronze and Stone" in Ci-poetry by Qingzhao, Beijing: People's Literature Publishing House, 2005, p. 153.

[7] Jiaosheng Wang, The Complete Ci-poems of Li Qingzhao: A New English Translation, Philadelphia: Department of Oriental Studies, University of Pennsylvania, 1989, p. 46.

[8] "Sappho: text," Sappho and Alcaeus, in Greek Lyric, trans. D. A. Campbell. Loeb Classical Library, [2]vol. 1, Cambridge, Mass. and London, 1982, pp. 123-124. 